\title{
INIBIÇÃO DOS LENTIVÍRUS DE PEQUENOS RUMINANTES POR DROGAS ANTIVIRAIS
}

\section{S.A.C. de Araújo ${ }^{1}$, R.R.Pinheiro ${ }^{2}$, T.V.M. Dantas ${ }^{1}$, A. Andrioli ${ }^{2}$, F.E.S. Lima ${ }^{1}$, R.P. Dias ${ }^{3}$, C.C. Campello ${ }^{1}$, E.C. Costa $^{1}$, A.R.F. Ricarte ${ }^{1}$, V.S.P. de Melo ${ }^{1}$, B.N. Rolim ${ }^{1}$, J.B.A. da Silva ${ }^{4}$, M.F.S. Teixeira ${ }^{1}$}

${ }^{1}$ Universidade Estadual do Ceará, Av. Paranjana, 1700, CEP 60740-000, Fortaleza, CE, Brasil. E-mail: suzanaraujo@msn.com

\section{RESUMO}

Inibidores da enzima transcriptase reversa e da protease foram avaliados quanto ao seu efeito inibitório na replicação do Vírus da Artrite Encefalite Caprina (CAEV) cepa CAEV Cork e do vírus Maedi-Visna (MVV) cepa K1514 cultivados em células fibroblásticas de caprinos. Os fármacos utilizados foram: lamivudina, didanosina, estavudina, zidovudina, efavirenz, atazanavir e lopinavir/ritonavir. A maior concentração utilizada para lamivudina, estavudina, zidovudina e efavirenz foi $500 \mu \mathrm{M}$, para atazanavir foi $50 \mu \mathrm{M}$ e 5,0 $\mu \mathrm{M}$ para lopinavir/r e didanosina. A atividade antiviral in vitro foi pesquisada por meio da avaliação da viabilidade celular através da redução do MTT e pela pesquisa de inibição dos efeitos citopáticos (CPE) dos vírus. A replicação dos vírus só não foi completamente bloqueada pelos inibidores de protease (IP) atazanavir e lopinavir/r enquanto os demais apresentaram eficácia antiviral significativa em diferentes concentrações. Os IP juntamente com o efavirenz, não mostraram atividade antiviral quando foram avaliados pela técnica de redução do MTT. Esses dados indicam que os fármacos inibidores da transcriptase reversa lamivudina, didanosina, estavudina e zidovudina são eficazes na inibição in vitro dos lentivírus de pequenos ruminantes.

PALAVRAS-CHAVE: Maedi-Visna, Artrite Encefalite Caprina, inibidores da transcriptase reversa, inibidores da protease.

\section{ABSTRACT}

INHIBITION OF SMALL RUMINANT LENTIVIRUS BY ANTIVIRAL DRUGS. Inhibitors of the reverse transcriptase and protease enzymes were evaluated for their inhibitory effect on the replication of caprine arthritis encephalitis virus (CAEV) strain CAEV Cork and of the MaediVisna virus (MVV) strain K1514 cultured in fibroblastic cells. The drugs lamivudine, didanosine, stavudine, zidovudine, efavirenz, atazanavir and lopinavir/ritonavir were used. The highest concentration used for lamivudine, stavudine, zidovudine and efavirenz was $500 \mu \mathrm{M}$, for atazanavir it was $50 \mu \mathrm{M}$ and $5.0 \mu \mathrm{M}$ for lopinavir/r and didanosine. The in vitro antiviral activity was investigated by evaluating the cell viability by the MTT method and testing for inhibition of cytopathic effects (CPE) of the virus. The replication of the virus was not completely inhibited by the protease inhibitors atazanavir and lopinavir/ $r$ in the test for CPE, while the others drugs showed significant antiviral efficacy in different concentrations. The protease inhibitors together with the efavirenz did not show antiviral activity when they were assessed by the reduced MTT technique. These data showed that the reverse transcriptase inhibitor drugs lamivudine, didanosine, stavudine and zidovudine were effective in the in vitro inhibition of small ruminant lentivirus.

KEY WORDS: Maedi-Visna, caprine arthritis encephalitis, inhibitors of the reverse transcriptase, inhibitors of the protease.

\section{INTRODUÇÃO}

Os Lentivírus de Pequenos Ruminantes (LVPR) são constituídos pelos Vírus da Artrite Encefalite
Caprina (CAEV)e Maedi-Visna (MVV) (HAASE, 1986). Esses vírus causam enfermidades que apresentam caráter crônico e são responsáveis por significativas perdas econômicas, uma vez que sua principal forma

${ }^{2}$ Embrapa Caprinos, Sobral, CE, Brasil.

${ }^{3}$ Universidade Estadual Vale do Acaraú, CE, Brasil.

${ }^{4}$ Universidade Federal Rural do Semiárido, Mossoró, RN, Brasil. 
de controle baseia-se na eliminação dos animais soropositivos. Esses retrovírus possuem a enzima transcriptase reversa (RT), permitindo ao RNA viral dar origem à dupla fita de DNA proviral capaz de incorporar aogenoma celular, além da enzima protease, responsável pela produção de vírions infecciosos maduros durante a replicação. Essas enzimas funcionam como alvos potenciais dos agentes antivirais (PeçAnHaetal., 2002;SouzA;Almeida, 2003). Noentanto, até o presente momento, as vacinas e os tratamentos para essas enfermidades têm se mostrado ineficazes.

Tem-se visto que a maioria das pesquisas com drogas antivirais visa ação contra as lentiviroses de primatas, que incluem os vírus da imunodeficiência humana (HIV) e símia (SIV) e em menor grau o vírus da imunodeficiência felina (FIV). Poucos estudos têm sido realizados com compostos ativos contra as lentiviroses em ungulados que abrange o CAEV, o MVV e o vírus da imunodeficiência bovina (BIV). Contudo, é possível se verificar um interesse cada vez maior em comparar a susceptibilidade destes vírus a drogas anti-HIV visto que eles apresentam similaridade molecular e biológica.

Por outrolado, drogas utilizadas com êxito no tratamentodeinfecções porvírus DNAeRNA poderiamser investigadas com relação à suas atividades contra os LVPR. Dentre essas encontram-se os nucleosídeos inibidoresdaenzimaRTcomoazidovudina,lamiduvina; osinibidoresnãonucleosídicos daRT comooefavirenz; os inibidores da enzima protease como o lopinavir/ ritonavir e o atazanavir. No tratamento de lentiviroses animais, a zidovudina tem demonstrado resultados positivos contra o vírus da imunodeficiência felina (HARTMANN, 1998).

É possível encontrar na literatura alguns trabalhos que demonstram ação de drogas anti-HIV contra a replicação do MVV através da análise do efeito citopático em cultivo de células do plexo coroide (THORMAretal.,1993; Thormaretal., 1995), verificando que os análogos nucleosídeos acíclicos bem como o 2', 3'-dideoxinucleosídeos apresentaram ação anti-MVV significativa. Análogos da citidina e outros fármacos com potencial ação antiviral e/ou antileucêmico foram testados sobre a replicação do MVV (SALVATORI et al., 2001) observando que estas classes de drogas desempenharam uma efetiva inibição do MVV.

Diante do exposto, objetivou-se avaliar o efeito antiviral in vitro defármacos antivirais contra os LVPR.

\section{MATERIALEMÉTODOS}

\section{Drogas}

As drogas antivirais utilizadas foram: os inibidores da transcriptase reversa zidovudina ou AZT (3'-azido-
3'- desoxitimidina), a didanosina (2', $3^{\prime}$ didesoxiinosina ou ddI), a lamivudina (3TC), a estavudina (2',3'-didehidro-3'-deoxitimidina ou D4T), o efavirens, os inibidores da protease atazanavir e o lopinavir/ritonavir gentilmente cedidas pelo Laboratório Farmacêutico dePernambuco (LAFEPE) epelo Hospital São José (Fortaleza, CE).

\section{Vírus}

Foram utilizadas amostras dos lentivírus CAEV Cork(Corketal.,1974)eMaedi-Visna K1514(SIGURDSSON etal.,1960), apresentando títulos de $10^{5,3} \mathrm{e} 10^{4,2} \mathrm{TCID}_{50}$ / $\mathrm{mL}$, respectivamente.

\section{Titulação do vírus}

A infectividade viral foi titulada pela inoculação da suspensão viral, ao décimo, em monocamada celular de fibroblastos em placas de 96 poços. Adicionou-se $100 \mu \mathrm{L}$ da diluição do vírus em cada poço. A placa foi incubada em estufa a $37^{\circ} \mathrm{C}$ com $5 \%$ de $\mathrm{CO}_{2}$ e os efeitos citopáticos (CPE) foram avaliados com 14 dias após a infecção. Os títulos virais foram calculados pelo método de ReED; MuenCH (1938).

\section{Cultivo celular}

Células primárias da membrana sinovial caprina foram obtidas por explante da articulação carpal de um animal sorologicamente negativo pela imunodifusão em gel de agarose(IDGA) para LVPR. As células foram cultivadas em meio essencial mínimo (MEM) contendo penicilina, estreptomicina e anfotericina B, suplementado com $10 \%$ de Soro Fetal Bovino (SFB). Após formação da monocamada celular, as células foram tripsinizadas e mantidas para uso após $3^{a}$ passagem. A concentração do SFB foi reduzida para $2 \%$ quando a cultura foi submetida à inoculação viral.

\section{Teste de citotoxicidade}

O efeito dos fármacos antivirais na proliferação dos fibroblastos foi determinado anteriormente por ARAújo et al. (2008) através do método de redução do MTT (brometo de 3-(4,5)-dimetiltialzolil -2,5 difeniltetrazólio) (Sigma, EUA).

\section{Atividade antiviral}

Em todos os testes de avaliação antiviral os fármacos foram utilizados nas concentrações não citotóxicas determinadas a priori. A maior concentração utilizada para lamivudina, estavudina, zidovudina e efavirenz foi $500 \mu \mathrm{M}$, para atazanavir 
foi $50 \mu \mathrm{Me}$ 5,0 $\mu \mathrm{M}$ para lopinavir/redidanosina.Para pesquisar a atividade antiviral dos fármacos foram realizados os seguintes testes:

a) Avaliação da viabilidade celular pela redução doMTT;

b) Pesquisa de inibição dos efeitos citopáticos. $\underline{\mathrm{MTT}}$

Avaliação da viabilidade celular pela redução do

Foram utilizadas microplacas de 96 poços, sendo que em cada poço depositou-se $100 \mathrm{~mL}$ de uma suspensão celular a uma concentração de $2 \times 10^{5}$ céls $/ \mathrm{mL}$ contendo MEM com 10\% de SFB. Após adesão das células e formação da monocamada, o meio decultivo foi retirado, sendo então adicionada em cada poço alíquotas do vírus na concentração de 10 TCID $_{50}$ (Dose Infectante para Cultura de Tecido 50\%). Essas células ficaram incubadas $3^{\circ} \mathrm{C}$, por 1 hora, para que ocorresse a adsorção viral. Após esse período, o meio de cultivo foi substituído por MEM suplementado com $2 \%$ deSFB e com as diferentes concentrações dos fármacos a serem testados, exceto o grupo controle negativo que recebeu apenas MEM e o controle positivo no qual se adicionou o vírus e o meio sem adição dos fármacos. As placas foram incubadas a $37^{\circ} \mathrm{C}$ em estufa de $\mathrm{CO}_{2}$ por 7 dias. No tocante à metodologia de redução do MTT, essa foi realizada de acordo como descrito por ANDRIGHETTI-FRÖHNER et al. (2003). A absorbância foi lida em espectrofotômetro (Bio-Rad, Modelo 680, EUA) com o comprimento de onda de 490nm. O percentual de proteção teve seu cálculo baseado na seguinte fórmula:

[(A-B)/(C-B)x100], ondeA, BeCindicamaabsorbância do extrato, vírus e controle celular, respectivamente.

\section{Pesquisa de inibição dos efeitos citopáticos}

A preparação das placas de 96 poços e a adição dos vírus foi semelhante à descrita para a realização da prova de redução do MTT. Após o período de incubação de 7 dias, o sobrenadante foi descartado e as monocamadas das placas foram coradas com Cristal Violeta, para avaliação dos CPE em microscópio invertido.

\section{Análise estatística}

Todos os experimentos foram realizados em quadruplicata e os resultados representam a media \pm desvio padrão. Inicialmente os dados foram submetidos aos testes de Sharpiro-wilk e Bartlett para avaliar a distribuição normal e homogeneidade da variância entre os tratamentos. Quando atendidas as condições necessárias para análise de variância esta foi executada através do procedimento GLMdo programaSAS (1999) e as médias comparadas pelo teste Student NewmanKeuls(SNK).Noscasosdeheterocedasticidade, mesmo após transformação logarítmica, angular ou radicial dos dados, as análises foram realizadas por meio do teste não-paramétrico de Kruskal-Wallis.

\section{RESULTADOSEDISCUSSÃO}

Para simular o tratamento de uma infecção estabelecida, as drogas antiretrovirais foram adicionadas após infecção das células fibroblásticas com as cepas CAEVCoeMVVK1514 e o resultado da inibição dos CPE avaliado após 7 dias de incubação. Na determinação da citotoxicidade verificou-se que a lamivudina, a estavudina, a zidovudina e o efavirens apresentaram concentração citotóxica média $\left(\mathrm{CC}_{50}\right)$ de $500 \mu \mathrm{M}$. A CC ${ }_{50}$ para lopinavir/r e didanosina foi $5 \mu \mathrm{M}$ e para o atazanavir de $50 \mu \mathrm{M}$ (ArAújoet al.,2008). Portanto, essas representam as maiores concentrações utilizadas para avaliação da inibição dos LVPR in vitro em fibroblastos. Como concentração inibitória média $\left(\mathrm{CI}_{50}\right)$ considerou a menor concentração capaz de inibir a replicação dos LVPR.

Os análogos nucleosídicos inibidores da transcriptase reversa(NRTIs) lamivudina, estavudina ezidovudina inibiram significativamente olentivírus caprino. A zidovudina com concentração inibitória média $\left(\mathrm{CI}_{50}\right)$ de $0,5 \mu \mathrm{M}$, enquanto a estavudina e a lamivudina apresentaram $\mathrm{CI}_{50}$ de $0,005 \mu \mathrm{M}$. Quantoà ação de inibição do lentivírus ovino, além dos NRTIs lamivudina, estavudina, didanosina e zidovudina o não nucleosídico efavirens foram significativamente eficazes, demonstrando $\mathrm{CI}_{50}$ de $0,05 \mu \mathrm{M}$ para zidovudina e efavirens. A lamivudina e a didanosina expressaram $\mathrm{CI}_{50}$ de $0,005 \mu \mathrm{M}$ e a estavudina de 0,5 $\mu \mathrm{M}$. Por outro lado, os inibidores de protease, atazanavir e lopinavir/r não foram capazes de inibir significativamente os CPE dos LVPR. Esses dados corroboram com os resultados encontrados por THORMAR et al. (1993) nos quais verificam que a zidovudina e a estavudina inibiram a replicação do MVV cepa K796 e diferem daqueles encontrados por DAHLBERG et al. (1987) que constataram que fármacos altamente eficazes contra o HIV, como a zidovudina ea estavudina, não demonstraram atividade contra a replicaçãodoCAEV,enquantoalgunsdideoxinuclesídeos foram altamente eficazes. Estes autores sugerem que esses achados podem decorrer da diferença existente entre o CAEV e o HIV quanto à susceptibilidade aos fármacos ou pela diferença entre os tipos celulares utilizados em cada experimento. No que diz respeito ao tipo celular, neste trabalho foram utilizados fibroblastos provenientes de membrana sinovial caprina, visto que eles são susceptíveis a infecção e multiplicação das cepas padrões utilizadas que foram CAEVCo da artrite encefalite caprina e MVV / K1514 do vírus Maedi-Visna. ThORMAR et al. (1993), 
utilizaram células de plexo coroide, pois buscavam a similaridade das reações neurológicas com os pacientes de HIV comparados aos de visna dos ovinos, além disso as cepas virais foram Visna K796 e isolados de ovinos islandeses com pneumonia denominadas de M88 e M34. SALVATORI et al. (2001) utilizaram também células do plexo coroide de ovi- nos; o clone neurovirulento KV1772 e amostra MV1514.

No tocante aos fármacos antivirais, SALVATORI et al. (2001) utilizaram onze drogas dentre elas a zidovudina, enquanto THORMAR et al. (1993) utilizaram 23 fosfatos nucleosídicos acíclicos entre os quais a didanosina.

\section{口Lamivudina $\square$ Estavudina $\square$ Zidovudina $\square$ Efavirens}

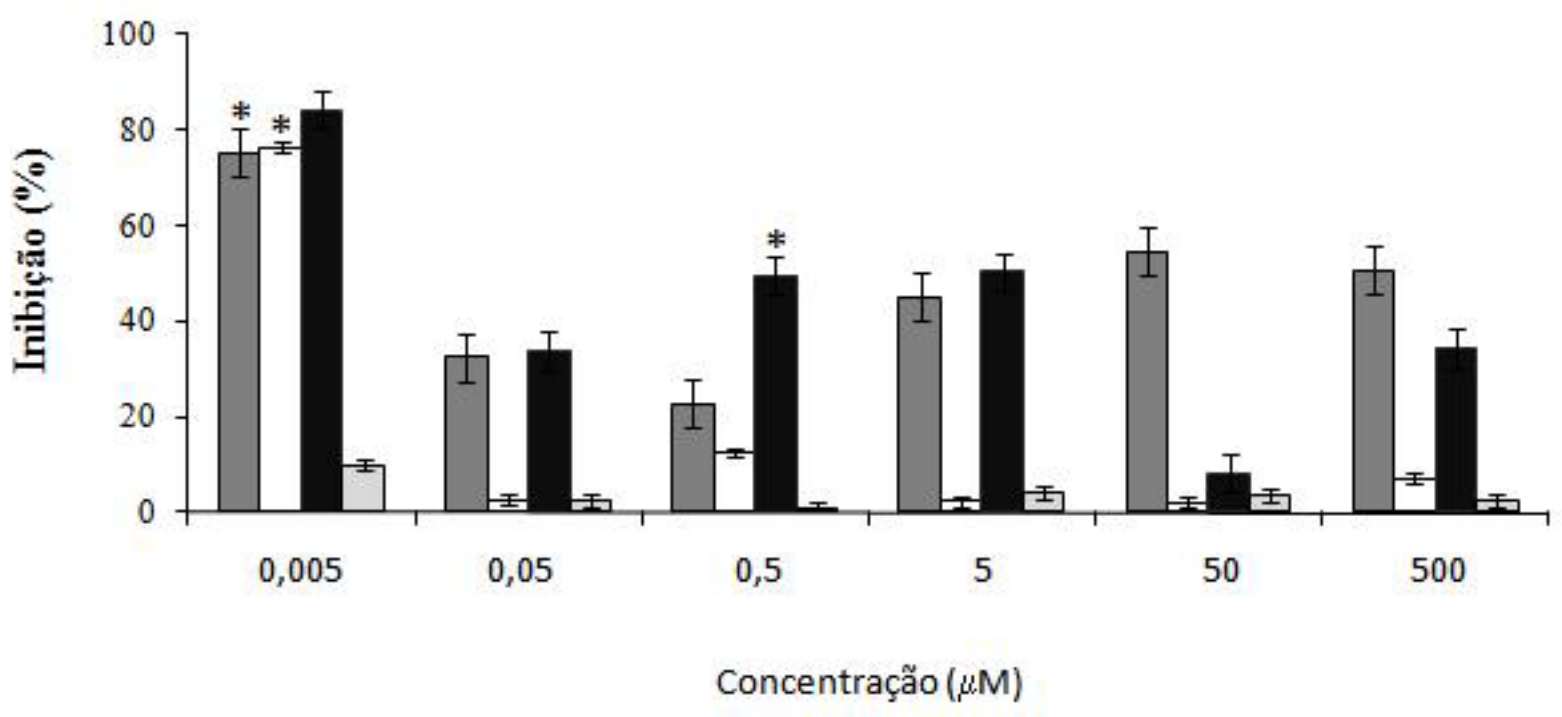

Fig. 1 - Efeito dos fármacos inibidores da transcriptase reversa sobre o CAEV.

\section{口Lamivudina $\square$ Estavudina $\mathbf{Q}$ Zidovudina $\square$ Efavirens}

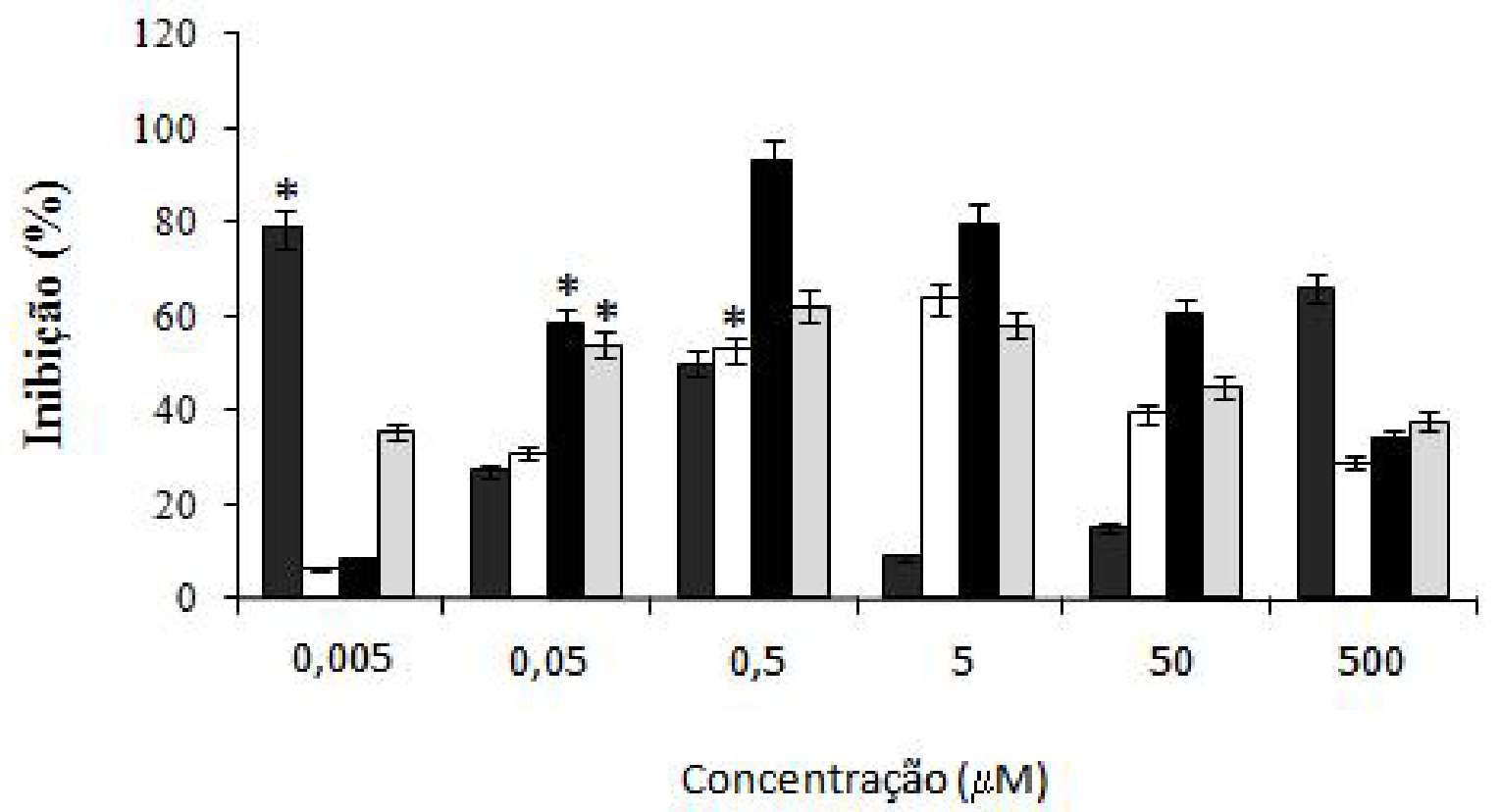

Fig. 2 - Efeito dos fármacos inibidores da transcriptase reversa sobre o MVV. 
$\square$ Didanosina x MVV $\square$ Lopinavir/r x MVV

$\square$ Didanosina x CAEV $\square$ Lopinavir/r x CAEV

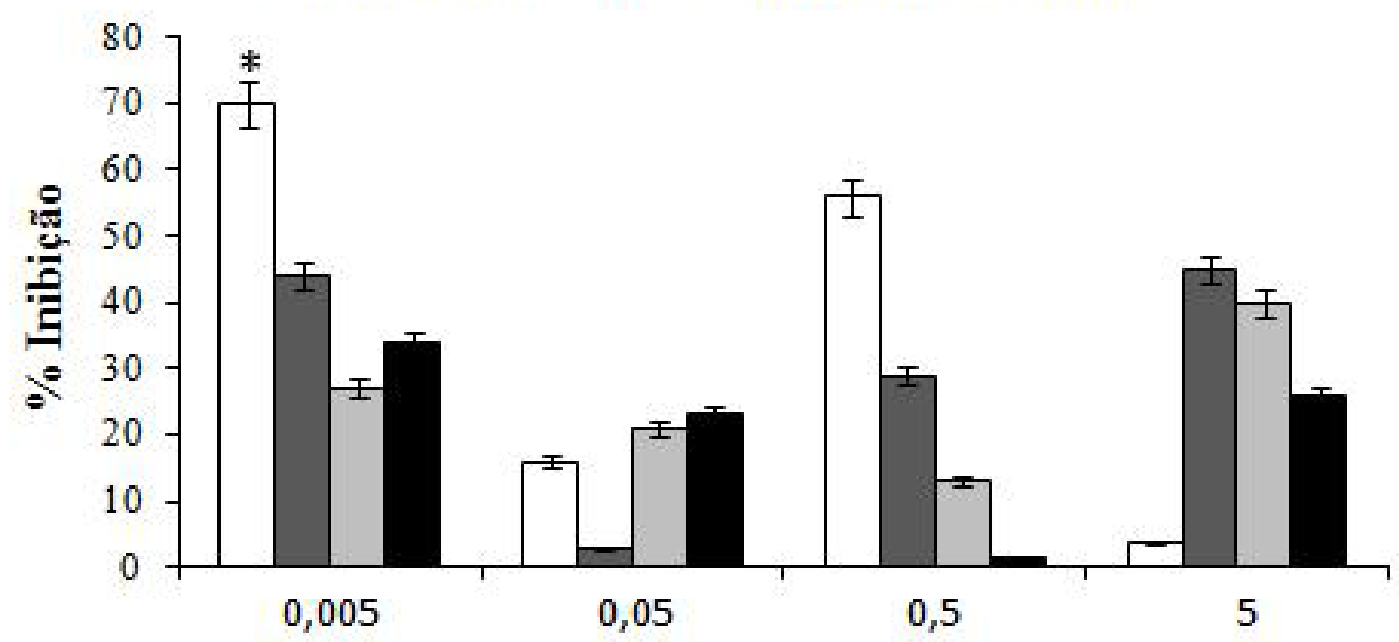

Fig. 3 - Efeito inibitório dos fármacos antivirais didanosina e lopinavir/r sobre o CAEV e o MVV.
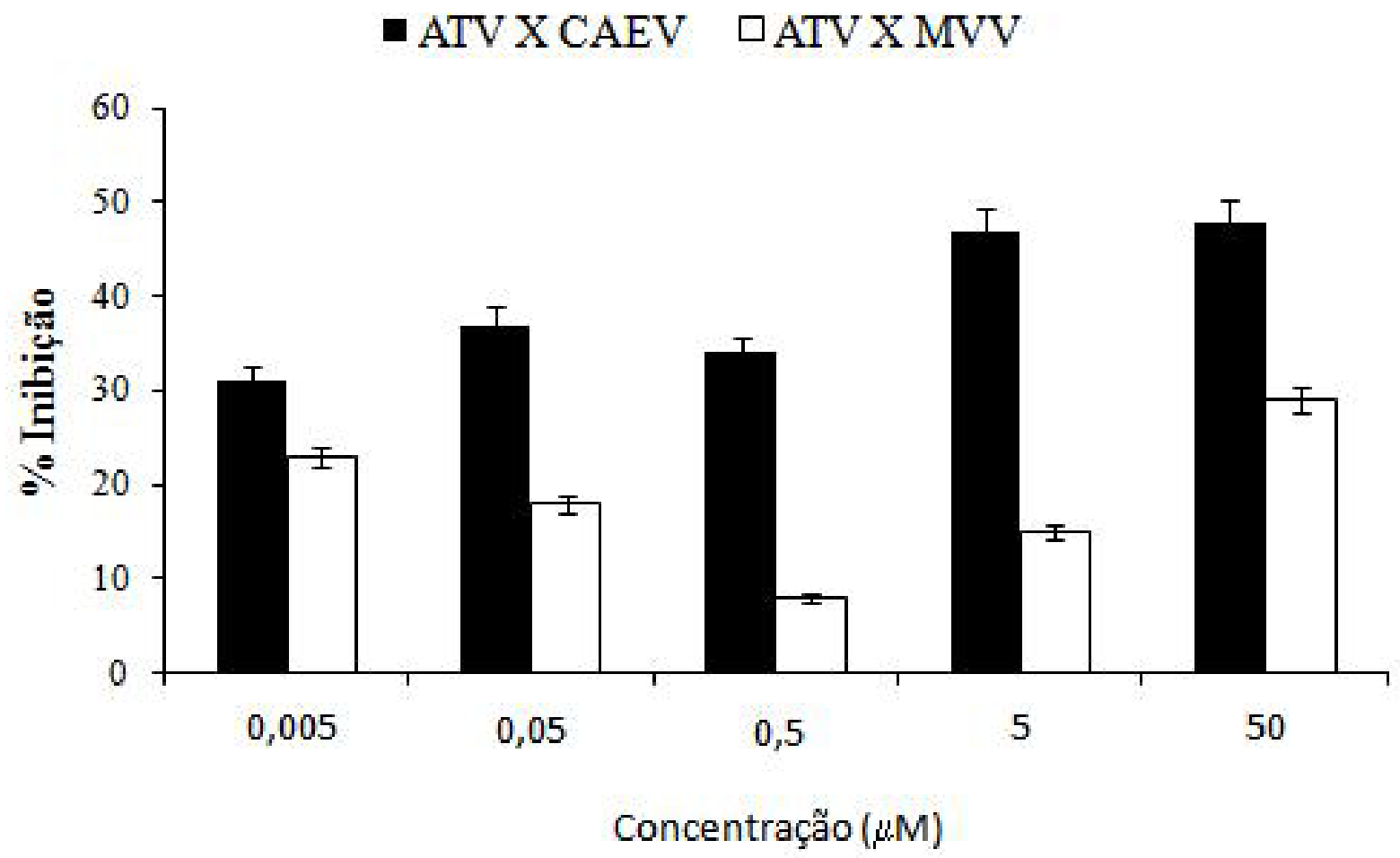

Fig. 4 - Efeito antiviral do inibidor de protease atazanavir sobre o MVV e o CAEV.

As divergências na atividade antiviral dos NRTIs em tipos celulares diversos dependem da afinidade desses fármacos com as quinases que estãoenvolvidas na conversão metabólica do composto para a forma de trifosfato (Witvrouw et al., 2000; BALINT, 2001).

Os NRTIs inibem a replicação do ácido nucleico através da inibição de enzimas das vias metabólicas das purinas ou pirimidinas pela inibição das polimerases utilizadas na replicação do ácido nucleico. Além disso, alguns análogos podem ser incorporados aoácido nucleico ebloquear sua síntese ou alterar sua função (BROOKs et al., 2000). Esses análogos nucleosídeos, para ficarem ativos, necessitam sofrer fosforilação intracelular para se converterem à 
forma 5'-trifosfato atuando como inibidor competitivo ou substrato alternativo para a transcriptase reversa (De Clerce, 2005). A ausência ou redução da fosforilação intracelular justifica o fato da porcentagem de inibição da replicação viral para algumas drogas ser maior na concentração mais baixa. Essa ausência e/ou redução da fosforilação intracelular pode ser resultado da ação citopática das cepas virais. Seo inibidor for incorporado à cadeia de DNA, tornase impossível a continuidade do seu crescimento. Assim, os NRTIs funcionam como terminadores de cadeia (Witvrouw et al., 2000; BALINT, 2001). Análogos de nucleosídeos incapazes de serem convertidos em nucleotídeos são fatalmente inativos.

Quandoa forma deavaliação da atividadeantiviral foi a redução do MTT, a lamivudina, a estavudina e a zidovudina inibiram significativamente o CAEV na concentração de 0,005 $\mu \mathrm{M}$ com um percentual de inibição acima de $70 \%$. Por sua vez, o efavirenz não foi capaz de inibir esse vírus nas concentrações avaliadas (Fig. 1). No que diz respeitoà ação desses fármacos contra o MVV, observa-se que a lamivudina e a zidovudina apresentaram ações significativas nas concentrações de 0,005 e $50 \mu \mathrm{M}$, respectivamente. Apesar da estavudina apresentar uma inibição de $63 \%$ na concentração de 5,0 $\mu \mathrm{M}$, essa não foi significativa. O efavirenz, à semelhança dos resultados para o CAEV, não mostrou ação significativa sobre o lentivírus ovino (Fig. 2).

A didanosina não inibiu significativamente o CAEV apesar da inibição de $52 \%$ na concentração de 0,005 $\mu \mathrm{M}$, porém nessa mesma concentração verificou-se uma inibição significativa contra o MVV (Fig. 3). De forma análoga ao teste de inibição dos CPE o lopinavir/r (Fig. 3) e atazanavir não indicaram atividade antiviral expressiva contra os LVPR, apesar desse fármaco apresentar 59\% de inibição do CAEV na concentração de $5 \mu \mathrm{M}$ (Fig. 4). Como os inibidores de protease atuam na fase final do ciclo de replicação viral, a falta de atividade antiviral dos inibidores de proteaselopinavir/reatazanavir sugere que os LVPR encontravam-se nas células infectadas na forma próviral. Visto que a protease, enzima alvo desses fármacos, é responsável pela clivagem das poliproteínas virais produzindo as proteínas estruturais finais dos LVPR (LE et al., 2001; MAK et al., 2003; OHTAKA; FREIRE, 2005; SAFrIN, 2008).

Entre os testes utilizados na avaliação da atividade antiviralobserva-se uma similaridadeentre os resultados, com exceção do fármaco efavirenz que, ao contrário dos resultados apresentados na prova de pesquisa de inibição dos CPE, não mostrou eficácia contra os LVPR quando avaliado pela técnica de redução do MTT. Ademais, comparando os resultados obtidos em ambas as técnicas, verifica-se que as concentrações eficazes foram diferentes para alguns fármacos. Essas diferenças na atividade antiviral podem ser explicadas pela utilização de uma técnica de avaliação subjetiva como na pesquisa de inibição dos CPE.

SMEE et al. (2002) afirmaram que, algumas vezes, a técnica do MTT pode mascarar a ação de certas substâncias, uma vez que, à exigência de conversão enzimática pelas células viáveis, é possível que certos compostos inibam esse processo fazendo com que alguns compostos sejam mais ou menos ativos do que eles realmente são. Além disso, as discrepâncias entre os efeitos inibitórios desses fármacos provavelmente refletem as diferenças na conversão metabólica em células fibroblásticas.

Com exceção da multiplicidade de pesquisas existentescomoHIV, os estudosquevisamavaliaraaçãode fármacos contra as lentiviroses em animais ainda são escassos. No entanto, THORMAR et al. (1993) analisaram o efeito inibitório in vitro de análogos fosfonato nucleosídeo acíclico na replicação do Maedi-Visna verificando que a maioria dos fosfonatos nucleosídeo acíclico inibiu a replicação do MVV e que existe formaçãodeCPEnasconcentraçõesentre 0,2a1,8 $\mu \mathrm{M}$. THORMAR etal.(1995)avaliaram outrosagentes comaçãoanti-HIV comprovada contra a replicação do Maedi-Visna vírus (MVV) através da análise doefeito citopáticoem cultivo de células do plexo coroide, sendo possível constatar que os análogos nucleosídeos acíclicos, bem como o 2', 3'-dideoxinucleosídeos, mostraram açãoanti-MVV significativa. SALVATORI et al. (2001) testaram análogos da citidina e outros fármacos com potencial ação antiviral e/ou antileucêmico sobre a replicação do MVV, observando que essas classes de drogas desempenharam uma efetiva inibição do MVV. Outros fármacos como análogos deoxinucleosídeos e alguns nucleosídeos tiveram sua atividade antiviral testada contra o MVV eo herpesvírus bovino 1 (BHV-1) e foi possível averiguar que todos os compostos apresentaram boa atividade antireplicativa (SALVATORI et al., 2002).

\section{CONCLUSÕES}

Os inibidores da enzima transcriptase reversa inibiram in vitro a replicação dos LVPR, enquanto os inibidores da enzima protease não foram capazes de impedir a multiplicação dos LVPR. Desta forma, os resultados alcançados representam o alicerce para descoberta de uma terapêutica eficaz para a infecção ocasionada pelos LVPR, sendo imprescindível a avaliação in vivo da eficácia desses fármacos.

\section{AGRADECIMENTOS}

Ao Conselho Nacional de Pesquisa $(\mathrm{CNPq})$ e à Fundação Cearense de Apoio ao Desenvolvimento 
Científico Tecnológico(FUNCAP) peloapoiofinanceiro. Ao Laboratório Farmacêutico de Pernambuco (LAFEPE) e ao HospitalSãoJosé de Fortaleza-CE pela concessão dos fármacos e à Embrapa-CNPC pelo fornecimento das condições técnicas e estruturais.

\section{REFERÊNCIAS}

ANDRIGHETTI-FRÖHNER, C.R.; ANTONIO, R.V.; CRECZYNSKI-PASA, T.B.; BARARDI, C.R.M.; SIMÕES, C.M.O. Cytotoxicity and potential antiviral evaluation of violacein produced by Chromobacterium violaceum. Memórias do Instituto Oswaldo Cruz, v.98, n.6, p.843-848, 2003.

ARAÚJO, S.A.C.; TEIXEIRA, M.F.S.; DANTAS, T.V.M.; MIRANDA, A.M.; LIMA, F.E.S.; MELO, V.S.P.; RICARTE, A.R.F.; COSTA, E.C. Avaliação in vitro da atividade citotóxica de drogas antivirais em fibroblastos caprinos. Ciência Animal, v.18, p.25-31. 2008.

BALINT, G.A. Antiretroviral therapeutic possibilities for human immunodeficiency virus/acquired immunodeficiency syndrome. Pharmacology \& Therapeutics, v.89. p.17-27, 2001.

BROOKS, G.F.; BUTEL, J.S.; ORNSTON, L.N.; JAWETZ, E.; MELNICK, J.L.; ADELBERG, E.A. Microbiologia médica. 21.ed. Rio de Janeiro: Guanabara Koogan, 2000. $670 \mathrm{p}$.

CORK, L.C.; HADLOW, W.J.; CRAWFORD, T.B.; GORHAM, J.R.; PIPER, R.C. infectious leukoencephalomyelitis of young goats. Journal of Infectious Diseases, v.129, p.134-141, 1974.

DAHLBERG, J.E.; MITSUYA, H.; BLAM, S.B.; BRODER, S.; AARONSON, S.A. Broad spectrum antiretroviral activity of 2',3'- dideoxynucleosides. Proceedings of the United State of Sciences, v.84, p.2469-2473, 1987.

De CLERCQ, E. HIV chemotherapy and prophylaxis: new drugs, leads and approaches. International of Journal Biochemistry and Cell Biology, v.2. p.581-591, 2005.

HAASE, A. T. The pathogenesis of lentivirus infections. Nature, v.322, p.130-136, 1986.

HARTMANN, K. Feline immunodeficiency virus infection: an Overview. The Veterinary Journal, v.155, p.123-137, 1998.

LE, V.; MAK, C.C.; LIN, Y.; ELDER, J.H.; WONG, C. Structure-activity studies of FIV and HIV protease inhibitors containing allophenylnorstatine. Bioorganic \& Medicinal Chemistry, v.9, p.1185-1195, 2001.

MAK, C.C.; BRIK, A.; LERNER, D.L.; ELDER, J.H.; MORRIS, G.M.; OLSON, A.J.; WONG, C. Design and synthesis of broad-based mono and bi-cyclic inhibitors of FIV and HIV proteases. Bioorganic \& Medicinal Chemistry, v.11, p.2025-2040, 2003.

OHTAKA, H.; FREIRE, E. Adaptive inhibitors of the HIV-1 protease. Progress in Biophysics and Molecular Biology, v.88, p.193-208, 2005.

PEÇANHA, E.P.; ANTUNES, O.A.C.; TANURI, A. Estratégias farmacológicas para a terapia anti-AIDS. Química Nova, v.25, n.6, p.1108-1116, 2002.

REED, L.; MUENCH, H. A simple method for estimating fifty per points. American Journal of Hygiene, v.27, p.413-497, 1938.

SAFRIN, S. Agentes antivirais. In: KATZUNG, B.G. (Ed.). Farmacologia básica e clínica. Rio de Janeiro: Guanabara Koogan, 2008. p. 717-735.

SALVATORI, D.; VINCENZETTI, S.; MAURY, G.; GOSSELIN, G.; GAUBERT, G.; VITA, A. Maedi-visna vírus, a model for in vitro testing of potential anti-HIV drugs. Comparative Immunology, Microbiology \&Infectious Diseases, v.24, p.113-122, 2001.

SALVATORI, D.; VOLPINI, R.; VINCENZETTI, S.; VITA, A.; COSTANZI, S.; LAMBERTUCCI, C.; CRISTALLI, G.; VITTORI, S. Adenine and deazaadenine nucleoside and deoxynucleoside analogues: inhibition of viral replication of sheep MVV (in vitro model for HIV) and bovine BHV-1. Bioorganic \& Medicinal Chemistry, v.10, p.2973-2980, 2002.

SAS INSTITUTE SAS/STAT. User's Guide, version 8. Cary, NC: SAS Institute Inc.. 1999.

SIGURDSSON, B.; THORMAR, H.; PALSSON, P. A. Cultivation of visna virus in tissue culture. Archiv fur die Gesamte Virusforschung, v.10. p.368-381, 1960.

SMEE, D.F.; MORRISON, A.C.; BARNARD, D.L.; SIDWELL, R.W. Comparison of colorimetric, fluorometric, and visual methods for determining anti-influenza (H1N1 and H3N2) virus activities and toxicities of compounds. Journal of Virological Methods, v.106, p.71-79, 2002.

SOUZA, M.V.N.; ALMEIDA, M.V. Drogas anti-HIV: passado, presente e perspectivas futuras. Química nova, v.26, n.3, p.366-372, 2003.

THORMAR, H.; BALZARINI, J.; HOLY, A.; JINDRICH, J.; ROSENBERG, I.; DEBYSER, Z.; DESMYTER, J.; De CLERCQ, E. Inhibition of visna virus replication by 2 ', 3'-dideoxynucleosides and acyclic nucleoside phosphonate analogs. Antimicrobial Agents and Chemotherapy, v.37, p.2540-2544, 1993.

THORMAR, K.; BALZARINI, J.; DEBYSER, Z.; WITVROUW, M.; DESMYTER, J.; De CLERCQ, E. 
Inhibition of visna virus replication and cytopathic effect in sheep choroids plexus cell cultures by selected anti-HIV agents. Antiviral Research, v.27, p.49-57, 1995.

WITVROUW, M.; PANNECOUQUE, C.; DESMYTER, J.; De CLERCQ, E.; ANDRIES, K. In vitro evaluation of the effect of temporary removal of HIV drug pressure. Antiviral Research, v.46. p.215-221, 2000.

Recebido em 23/1/09

Aceito em 23/5/10 